\title{
Design Strategy of Batak Socio-Cultural Park as a Tourist DESTINATION WITH LOCAL WISDOM APPROACH IN LAKE TOBA REGION
}

\section{Strategi Perancangan Taman Sosial Budaya Batak Sebagai Destinasi Wisata dengan Pendekatan Kearifan LoKal di KaWASAN DANAU TOBa}

\author{
Bernad Pasaribu ${ }^{1 *}$, Made Suastika², Sri Yuliani ${ }^{3}$ \\ Program Studi Arsitektur, Fakultas Teknik Universitas Sebeas Maret ${ }^{1 *}$ \\ Email : bernadpasaribu@ student.uns.ac.id \\ Program Studi Arsitektur, Fakultas Teknik Universitas Sebeas Maret ${ }^{2}$ \\ Program Studi Arsitektur, Fakultas Teknik Universitas Sebeas Maret ${ }^{3}$
}

\begin{abstract}
Indonesia is a country that has various ethnics and cultures. One of the tribes found in Indonesia is Batak tribe located in North Sumatra, Batak tribe can be divided into six sub-tribe of Batak Karo, Toba, Simalungun, Mandailinng, Angkola, Pakpak. In today's modern era, cultural degradation has caused the values of the nation being eroded so that these cultures need to be preserved to avoid them from extinction. This study describes the idea of accommodating activities that are preserving the culture of the Batak tribe as a Batak socio-cultural park using local wisdom concept. Not only accommodate, Batak socio-cultural park is also functioned as a tourist destination which will support the main function of preserving culture and introducing Batak culture to the wider community. The design method used in this research was planning and design method by formulation of concept and transformation of concept into architectural design. The steps of research were by applying the Batak's local wisdom concept to the architecture of the Batak socio-cultural park building to give a traditional impression and be able to be an attraction for tourists to come to visit. The results of the research are strategies to design a Batak socio-cultural park as a tourist destination by accommodating elements of local wisdom.
\end{abstract}

Keywords: Batak, Local Wisdom, Socio-cultural Park, Tourist Destination.

\section{PENDAHULUAN}

Negara Indonesia merupakan suatu negara yang kaya akan berbagai macam suku dan budaya yang tentu saja memiliki kebudayaan yang beragam. Hal ini terbukti dengan jumlah suku bangsa yang ada di Indonesia secara keseluruhan mencapai lebihi dari 1.300 suku bangsa dan memiliki 1.211 bahasa di ana 1.158 di antaranya adalah Bahasa daerah.
Suku Batak merupakan salah satu terdapat di Indonesia yang terletak di provinsi Sumatera Utara. Suku Batak dapat digolongkan menjadi enam sub-suku yaitu: Batak Karo, Batak Simalungun, Batak Toba, Batak Mandailing, Batak Angkola, dan Batak Pakpak.

Suku Batak memiliki warisan kebudayaan yang mengandung nilai-nilai luhur bangsa. Terjadinya degradasi kebudayaan 
mengakibatkan terkikisnya nilai-nilai luhur tersebut. Sehingga muncullah gagasan untuk melestarikan dan menjaga kebudayaan Batak berupa Taman Sosial Budaya yang dipadukan dengan nilai-nilai kearifan lokal sebagai pendekatan desain.

Untuk menunjang fungsinya sebagai wadah pelestarian adat dan kebudayaan Batak, Taman Sosial Budaya Batak juga menjadi sebuah destinasi wisata yang akan dibuka untuk wisatawan sehingga diharapkan nantinya bisa memperkenalkan adat istiadat dan kebudayaan suku Batak kepada kalangan luas.

Pariwisata dan kebudayaan merupakan dua hal yang tidak dapat dipisahkan karena dalam pariwisata terjadi interaksi antara kebudayaan yang berbeda yaitu interaksi antara wisatawan dengan masyarakat setempat/lokal. Selain itu, dalam UU RI. No.10 tahun 2009 tentang kepariwisataan dijelaskan bahwa salah satu tujuan kepariwisataan yaitu memajukan kebudayaan.

Bagi negara Indonesia, peranan pariwisata sangat terasa setelah terjadinya penurunan penerimaan devisa dari hasil ekspor di bidang minyak dan gas, walaupun nilai nominalnya masih berada di bawah penerimaan devisa minyak dan gas, namun penerimaan devisa dari sektor pariwisata selama tahun 2011-2015 terus meningkat sementara sektor minyak dan gas bumi terus mengalami penurunan termasuk juga beberapa sektor lain. Hal ini dapat dilihat pada gambar 1 .

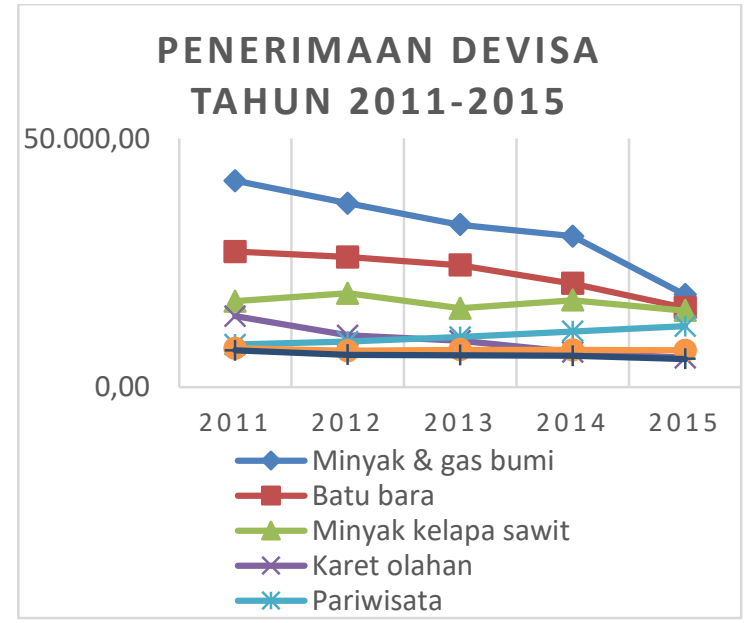

Gambar 1. Penerimaan devisa negara RI tahun 2011-2015

Sumber: www.kemenpar.go.id
Kawasan Danau Toba sebagai lokasi perancangan Kawasan strategis pariwisata nasional (KSPN) yang masuk dalam daftar 10 destinasi wisata prioritas Indonesia. Hal ini dapat menunjang fungsi Taman Sosial Budaya Batak sebagai wadah pelestarian adat istiadat dan kebudayaan suku Batak dan juga sebagai destinasi wisata.

Strategi desain yang diterapkan pada proyek ini yaitu pendekatan kearifan lokal. Strategi ini dipilih agar dapat menampilkan citra lokalitas yang nantinya bisa menjadi sebuah ciri khas daripada Taman sosial budaya Batak yang direncanakan.

Kerifan lokal yang terdapat di Indonesia bersumber dari beberapa elemen dasar yang dapat dilihat pada tabel 1 berikut.

Tabel 1. Sumber-Sumber Kearifan Lokal Di Indonesia

\begin{tabular}{|l|l|}
\hline Elemen Dasar & Kearifan Lokal \\
\hline \multirow{4}{*}{ Aspek Empiris } & Interaksi sosial manusia \\
\cline { 2 - 2 } & Habitat \\
\hline \multirow{5}{*}{ Simbol Budaya } & Arsitektur \\
\cline { 2 - 2 } Pengetahuan & Kesenian \\
\cline { 2 - 2 } & Kesusasteraan \\
\cline { 2 - 2 } & Ritual \\
\cline { 2 - 2 } & $\begin{array}{l}\text { Mersepsi logal logis pada } \\
\text { kearifan lokal }\end{array}$ \\
\cline { 2 - 2 } & $\begin{array}{l}\text { Persepsi non logis pada } \\
\text { kearifan lokal }\end{array}$ \\
\hline
\end{tabular}

Sumber: Meliono, 2016

Dari tabel di atas, maka nilai-nilai kearifan lokal dapat diklasifikasikan menjadi dua (Arimbi, Nugroho, \& Suparno, 2017), yaitu:

a. Fisik (tangible), seperti nilai-nilai yang terkandung dalam tata cara, ketentuanketentuan khusus yang dituangkan dalam bentuk catatan tertulis misalnya dalam bentuk kitab, bangunan-bangunan tradisional/arsitektur yang merupakan cerminan dari bentuk kearifan lokal misalnya rumah adat Batak (Jabu Bolon, Siwaluh Jabu, Pinar Horbou, Sopo Jojong/Jerro, dan Bagas Godang), bendabenda cagar budaya, dan juga kondisi lingkungan suatu daerah termasuk sebagai kearifan lokal.

b. Non fisik (intangible), kearifan lokal yang tidak berwujud ini dapat ditemui seperti pengetahuan lokal, nilai-nilai lokal seperti norma-norma yang terdapat di suatu daerah(interaksi sosial manusia), habitat, 
keterampilan lokal seperti kesenian tradisional,kesusasteraan, ritual, mitos lokal dan juga sumber daya lokal.

\section{METODE}

Metode yang digunakan adalah metode perencanaan dan perancangan (Thalia, Suastika, \& Pramesti, 2018).

\subsection{Metode Perencanaan}

Metode perencanaan yang digunakan dalam pembahasan permasalahan ini yaitu:

a. Eksplorasi

Bertujuan untuk mencari/menyusun ide-ide aupun gagasan-gagasan melalui fenomenafenomena yang terjadi di masyarakat maupun Batak maupun di tanah Batak. Fenomena-fenomena yang terjadi akan dipilah mana yang memiliki daya tarik kemudian dikembangkan menjadi sebuah ide/gagasan. Fenomena yang terjadi menunjukkan bahwa telah terjadi degradasi kebudayaan baik secara nasional maupun secara regional, sehingga diperlukan tindakan-tindakan untuk melestarikan kebudayaan tersebut.

b. Penyusunan ide

Tahap ini merupakan tahap lanjutan, setelah terkumpul ide-ide/gagasan yang sesuai, maka kemudian dirangkai/disusun sehingga memiliki visi dan misi yang jelas.

c. Pengumpulan data

Pada tahap pengumpulan data, bertujuan untuk mengumpulkan data-data atau informasi yang relevan tentang ide/gagasan yang telah disusun sehingga dapat menunjang proses perumusan konsep perencanaan dan perancangan. Adapun cara-cara yang dilakukan dalam pengumpulan data yaitu dengan kajian literatur, survey lapangan, wawancara, dan juga studi preseden.

d. Analisis data

Data yang telah terkumpul kemudian akan diolah/dianalisis menggunakan pendekatan kearifan lokal. Analisis tersebut berupa analisis pengguna dan kegiatan, analisis besara ruang, analisis tapak, analisis tampilan bangunan, analisis struktur, dan analisis utilitas.

e. Merumuskan konsep perencanaan dan perancangan

Konsep perencanaan dan perancangan merupakan kesimpulan dari hasil analisis data. Konsep perencanaan dan perancangan ini nantinya akan digunakan sebagai acuan dalam mendesain Taman Sosial Budaya Batak.

\subsection{Metode perancangan}

Metode perancangan yang digunakan dalam mendesain Taman Sosial Budaya Batak yaitu:

a. Transformasi desain

Transformasi desain merupakan tahap penerjemahan konsep perencanaan dan perancangan ke dalam bentuk desain.

b. Metode desain

Metode desain yang digunakan mengacu pada konsep perancangan arsitektur kearifan lokal sebagai pendekatan desain.

c. Metode pemodelan

Metode pemodelan yaitu cara-cara yang digunakan untuk menggambarkan konsep perencanaan dan perancangan, yaitu dengan cara: membuat sketsa ide, gambar Teknik (dalam format CAD), pemodelan 3 dimensi, rendering model.

Hasil akhir yang diperoleh merupakan model konseptual dan model fisik desain Taman Sosial Budaya Batak Sebagai Destinasi Wisata Dengan Pendekatan Kearifan Lokal Di Kawasan Danau Toba Sumatera Utara.

\section{HASIL DAN PEMBAHASAN}

Pada hasil dan pembahasan, akan dijelaskan mengenai penerapan kearifan lokal suku Batak pada Taman Sosial Budaya Batak.

\subsection{Peruangan}

Sesuai dengan fungsinya sebagai wadah untuk melestarikan dan edukasi warisan suku dan budaya Batak, maka dibutuhkan berbagai ruang agar dapat mewadahi kegiatan tersebut dengan baik. Berikut adalah tabel kelompok kegiatan dan kebutuhan ruang pada Taman Sosial Budaya Batak.

Tabel 2. Kebutuhan Ruang

\begin{tabular}{|l|l|}
\hline Kegiatan & Kebutuhan Ruang \\
\hline \multirow{4}{*}{ Penerimaan } & Entrance \\
\cline { 2 - 2 } & Area Parkir Pengelola \\
\cline { 2 - 2 } & Area Parkir Pengunjung \\
\hline \multirow{3}{*}{ Pelestarian } & R. Museum \\
\cline { 2 - 2 } & R. Peyimpanan \\
\cline { 2 - 2 } & R. Laboratorium \\
\hline
\end{tabular}




\begin{tabular}{|l|l|}
\hline & Taman Arsitektur Batak \\
\hline \multirow{3}{*}{ Pertunjukan } & R. Pertunjukan Indoor \\
\cline { 2 - 2 } & R. Pertunjukan Outdoor \\
\hline \multirow{4}{*}{ Pengelola } & R. Kepala \\
\cline { 2 - 2 } & R. Karyawan \\
\cline { 2 - 2 } & R. Rapat \\
\hline \multirow{3}{*}{ Pameran } & R. Pameran Tetap \\
\cline { 2 - 2 } & R. Pameran Temporer \\
\hline \multirow{5}{*}{ Servis } & Food court \\
\cline { 2 - 2 } & Souvenir shop \\
\hline & R. Pompa \\
\cline { 2 - 2 } & R. Genset \\
\cline { 2 - 2 } & R. Penyimpanan \\
\cline { 2 - 2 } & R. Lavatory \\
\hline
\end{tabular}

\subsection{Pengolahan Tapak}

\subsubsection{Lokasi dan Pencapaian}

Lokasi Taman Sosial Budaya Batak terletak di Kawasan Danau Toba, tepatnya di jalan Motung-Sibisa desa Pardamean Kecatan Ajibata Kabupaten Toba Samosir, Sumatera Utara seperti terlihat pada gambar 2. Luas tapak tapak sekitar $70.400 \mathrm{~m}^{2}$ dan kemiringan lahan antara 2-45 derajat.

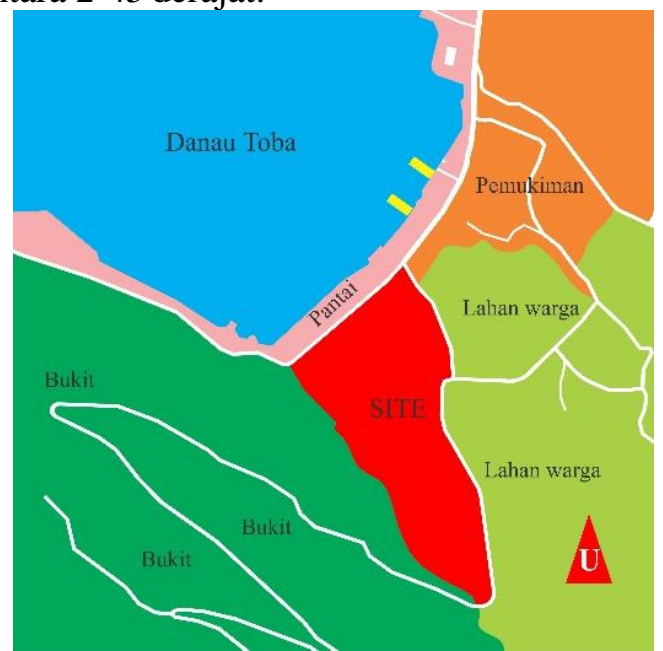

Gambar 2. Lokasi Tapak

Akses menuju tapak dibagi menjadi dua kelompok yaitu akses pengunjung dan akses pengelola seperti yang terlihat pada gambar 3 . Akses pengunjung dibagi menjadi dua, yaitu gerbang masuk dan juga gerbang keluar. Hal ini bertujuan untuk memberikan kenyamanan kepada pengunjung dalam mencapai maupun meninggalkan tapak. Akses pengunjung berada pada jalan utama yaitu jalan Motung-Sibisa yang terletak pada sisi Utara tapak sedangkan akses pengelola berada pada sisi sebelah Timur tapak.

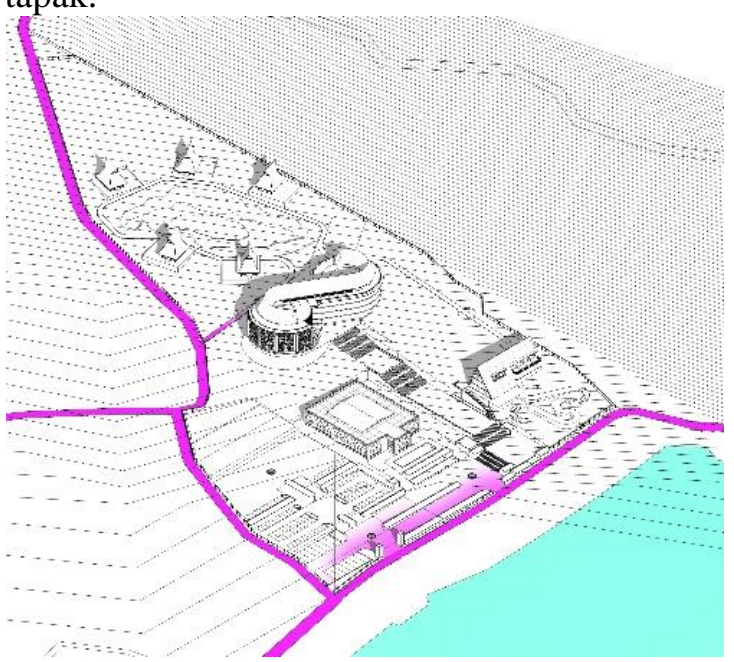

Gambar 3. Akses menuju Tapak

\subsubsection{Pemintakan (zoning)}

Zoning pada kawasan Taman Sosial Budaya Batak mengadopsi sistem kosmologi pada suku Batak, konsep kosmologi tiga banua (dunia) yaitu banua ginjang (dunia atas), banua tonga (dunia tengah), banua toru (dunia bawah). Konsep banua tersebut ternyata memiliki arti, dimana banua ginjang dipercayai merupakan tempat tinggal Tuhan sang maha pencipta penguasa langit dan bumi dilambangkan dengan warna putih, banua tonga yaitu tempat dimana manusia tinggal dan melakukan segala aktivitas dilambangkan dengan warna merah sedangkan banua toru dipercaya merupakan tempat tinggal iblis/mahluk-mahluk gaib yang dilambangkan dengan warna hitam.

Konsep tiga Banua tersebut juga diterapkan pada bangunan/rumah tradisional Batak yang merupakan rumah panggung seperti yang digabarkan pada gambar 4. Banua ginjang merupakan bagian atap berfungsi sebagai tempat menyimpan barang-barang/ bendabenda pusaka dan juga benda-benda berharga lainnya, banua tonga pada bagian badan/dingding rumah yang berfungsi sebagai tempat tinggal dan melakukan aktivitas, banua toru pada bagian kolong rumah berfungsi sebagai kendang ternak. 


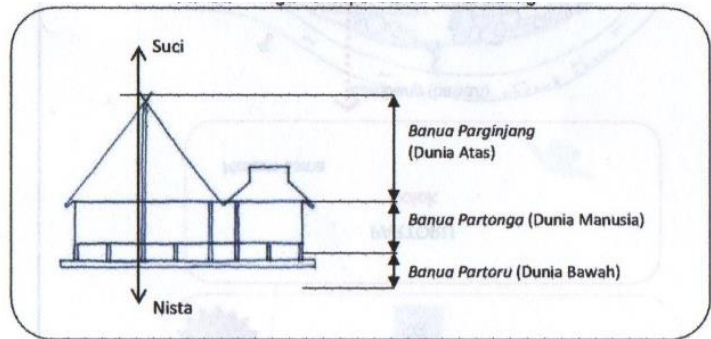

Gambar 4. Aplikasi Konsep Banua pada Rumah Tradisional Suku Batak

Sumber: Proceding seinar nasional the local tripod

Aplikasi konsep tiga banua pada kawasan Taman Sosial Budaya Batak yaitu banua toru meliputi area entrance dan area parkir, banua tonga meliputi area bangunan-bangunan utama, dan banua ginjang meliputi area taman arsitektur Batak.

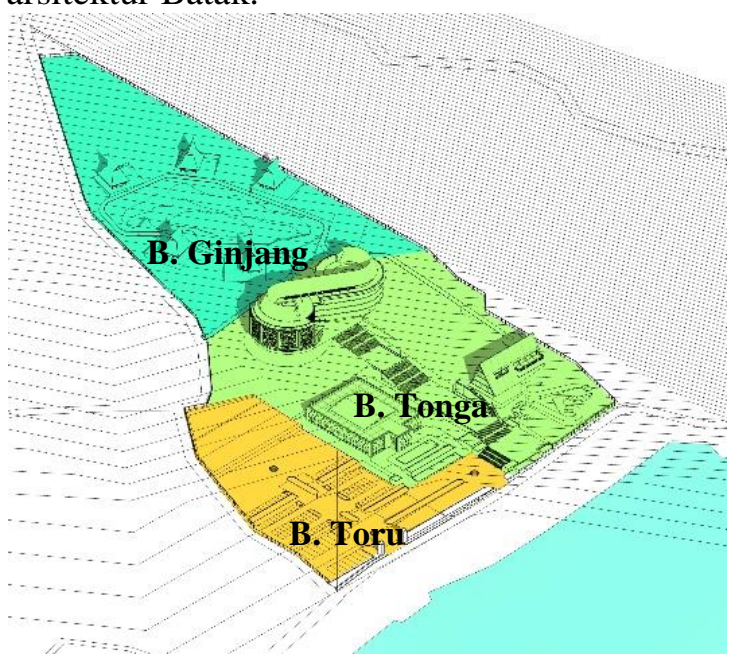

Gambar 5. Aplikasi Konsep Tiga Banua pada Kawasan

\subsubsection{Gubahan Massa}

Taman sosial budaya Batak terdiri dari beberapa massa. Dalam pengolahan gubahan massa pada Taman sosial budaya Batak ini menerapkan konsep dalihan natolu/rakut sitelu/daliken sitelu (tungku nan tiga) terlihat pada gambar 6.

Konsep tersebut diterapkan pada susunan/posisi bangunan-bangunan utama yaitu museum, foodcourt \& souvenir shop, dan sopo godang yang berada pada zona banua tonga.

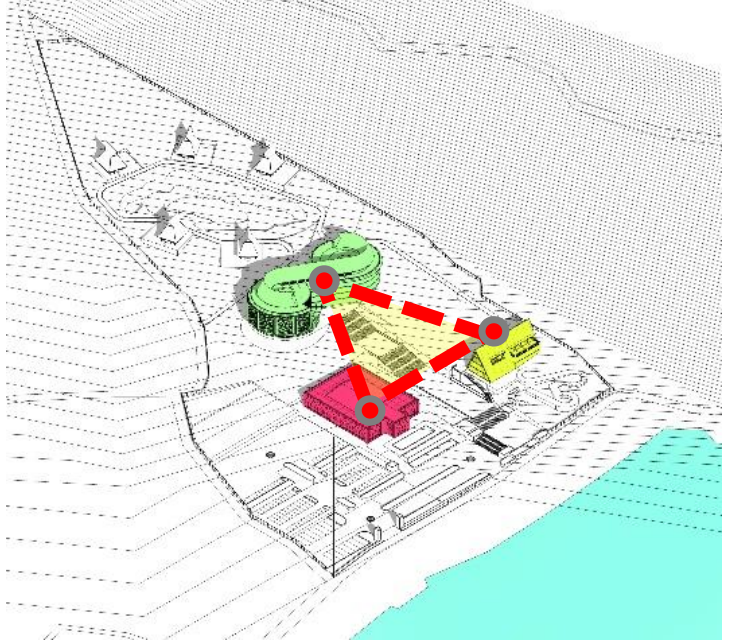

Gambar 6. Aplikasi Konsep Dalihan Natolu pada Penempatan Bangunan Utama

\subsubsection{Tampilan Bangunan}

Penggunaan elemen-elemen tradisional pada eksterior maupun interior bangunan merupakan strategi yang diterapkan untuk menciptakan citra lokalitas dan memperkuat identitas budaya suku Batak pada Taman soSial budaya Batak. Elemen-elemen tradisional yang diterapkan pada bangunan yaitu:

a. Motif ukiran/ornamen tradisional

Suku Batak memiliki berbagai macam ukiran tradisional dengan ciri yang berbedabeda pada setiap sub-sukunya. Ukiran tradisional tersebut dinamai Gorga/Gerga/Pinar. Contoh ornamen gorga dapat dilihat pada gambar 7. Ornamenornamen tersebut biasanya digunakan pada dingding rumah, alat-alat musik, dan juga kain tradisional.

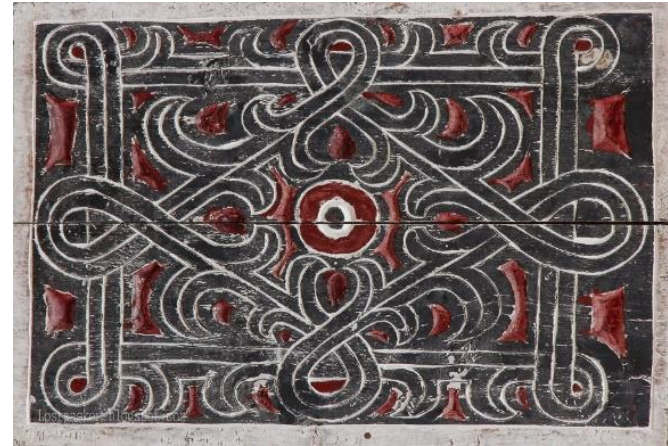

Gambar 7. Gorga desa na ualu

Sumber: Pengumpulan dan Dokumentasi Ornamen Tradisional Sumatera Utara (1980)

Ukiran gorga diaplikasikan pada fasad/eksterior maupun juga interior bangunan. Pada bagian eksterior bangunan 
Museum, ukiran gorga diaplikasikan pada kulit bangunan berupa secondary skin seperti yang terlihat pada gambar 8 . Pada bagian interior bangunan ornamen gorga diaplikasikan pada penutup kolom dan juga pada railing tangga seperti yang terlihat pada gambar 9.

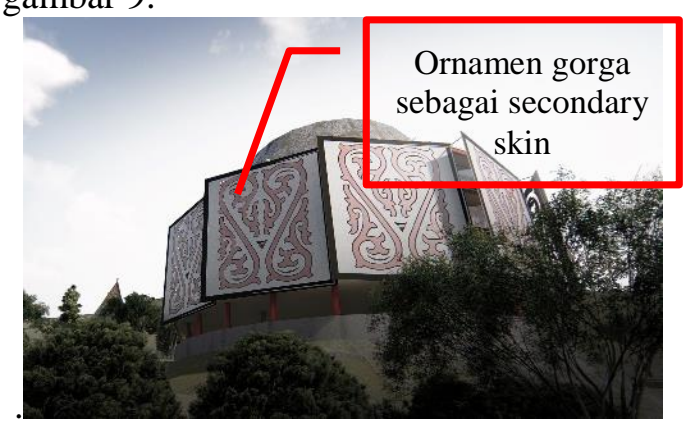

Gambar 8. Aplikasi Gorga pada Fasad Museum

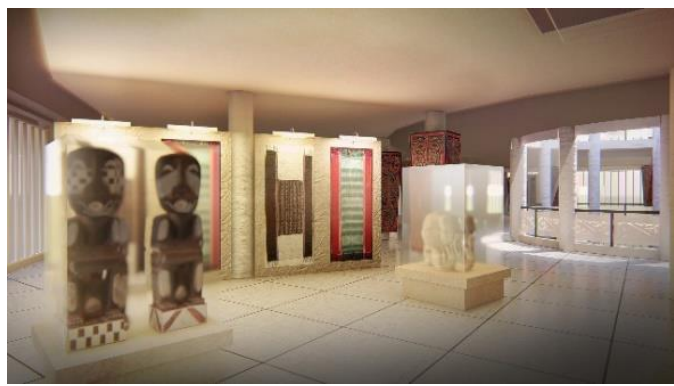

Gambar 9. Aplikasi Gorga pada Interior Museum

b. Material lokal

Pada zaman dahulu ijuk merupakan material yang lazim digunakan sebagai bahan penutup atap pada rumah suku Batak. Hal ini dikarenakan bahan ijuk yang berasal dari pohon aren sangat mudah ditemukan di tanah Batak.

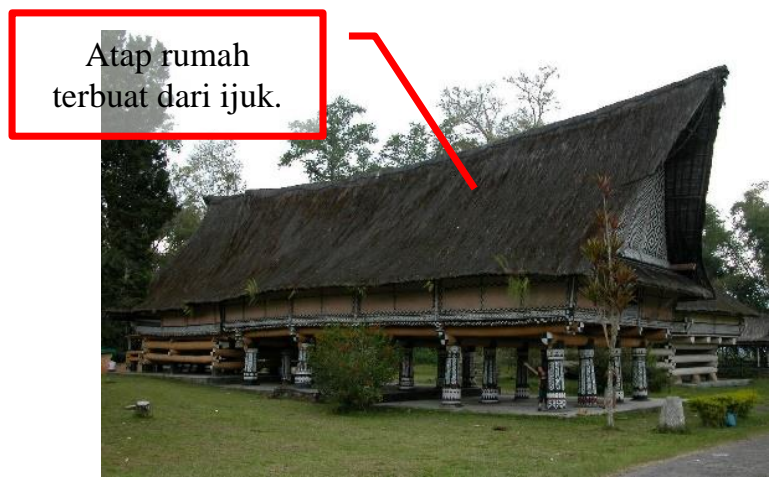

Gambar 10. Atap Ijuk pada Ruma Bolon Purba Sumber: Wikipedia.org
Penggunaan material ijuk pada Taman Sosial Budaya Batak juga diperuntukkan sebagai atap bangunan. Material ini diaplikasikan pada atap bangunan Museum seperti terlihat pada gambar 11 dan bangunan foodcourt terlihat pada gammbar 12. Hal ini bertujuan untuk memberikan kesan etnik/tradisional pada bangunan sehingga citra lokalitas pada bangunan semakin kental dan dapat menjadi ciri khas sekaligus daya tarik pada bangunan.

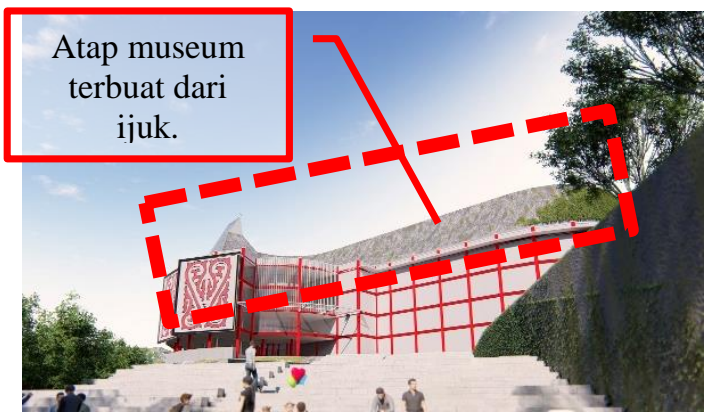

Gambar 11. Aplikasi Ijuk pada Atap Museum

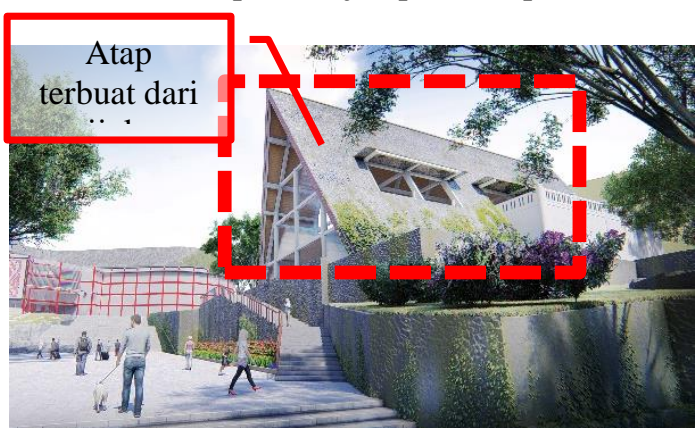

Gambar 12. Aplikasi Ijuk pada Atap Foodcourt \& Souvenir shop

c. Geometri segitiga dan persegi

Bentuk geometri yang lajim ditemui pada arsitektur tradisional suku Batak ialah bentuk segitiga dan juga segi empat. Geomerti tersebut merupakan geometri penyusun yang membentuk atap dan juga denah rumah yang yang berbentuk persegi Panjang yang memanjang dari depan hingga belakang bangunan, hal ini dapat dilihat pada gambar 13. 


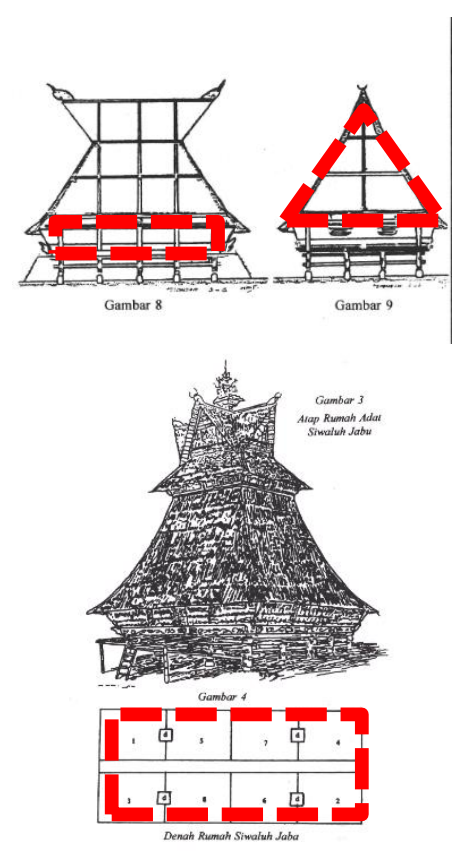

Gambar 13. Bentuk geometri pada rumah tradisional suku Batak Sumber: S. P. Napitupulu, 1997

Hal tersebut berdampak terhadap tipologitipologi bangunan yang tercipta pada era modern seperti yang terdapat pada bangunan bandara Silangit seperti yang terlihat pada gabar 14 dan juga beberapa bangunan lain di sumatera utara khususnya di tanah Batak, sehingga bentuk-bentuk geometri tersebut menjadi sangat familiar dan lazim digunakan di kalangan masyarakat suku Batak. Bentuk-bentuk geometri tersebut telah menjadi sebuah ciri khas dan melekat pada suku Batak yang dapat dikatakan sebagai sebuah kearifan lokal.

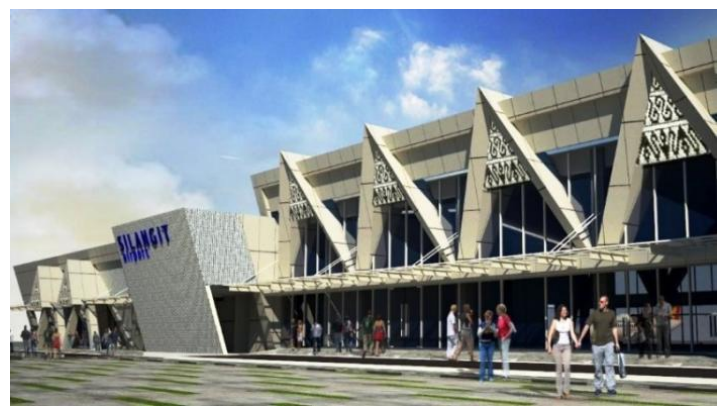

Gambar 14. Bentuk geometri pada arsitektur Bandara Silangit, Siborong-borong Sumber: S. P. Napitupulu, 1997

Bentuk-bentuk geometri tersebut kemudian diaplikasikan pada fasad bangunan foodcourt, dimana fasad bangunan foodcourt berbentuk segitiga seperti terlihat pada gambar 15. Bentuk bangunan foodcourt terisnpirasi dari bentuk atap rumah tradisional batak Toba yang kemudian dimodifikasi menjadi bentuk yang lebih sederhana berupa limas segitiga sehingga sekilas terlihat seperti rumah tradisional Batak Toba.

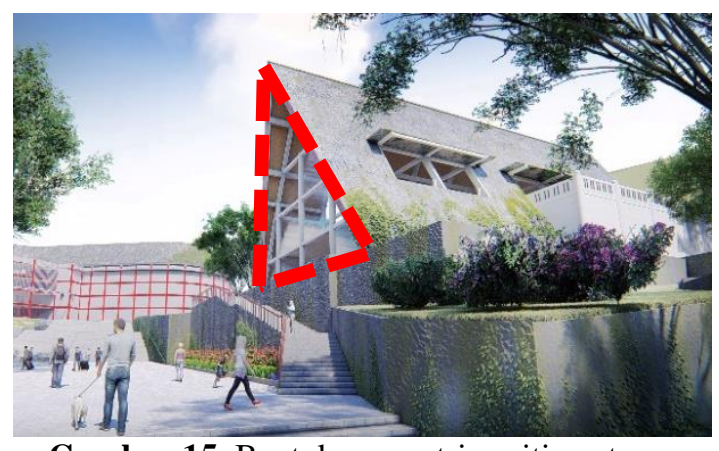

Gambar 15. Bentuk geometri segitiga atap foodcourt \& souvenir shop

Bentuk-bentuk geometri tersebut juga terdapat pada bangunan sopo godang (convention hall) seperti pada gambar 16. Fasad banguan berbentuk persegi panjang yang dikombinasikan dengan bentuk segitiga pada bagian dalamnya sehingga terlihat seperti susunan rumah Batak yang sedang berjejer lurus seperti pada perkampungan Batak.

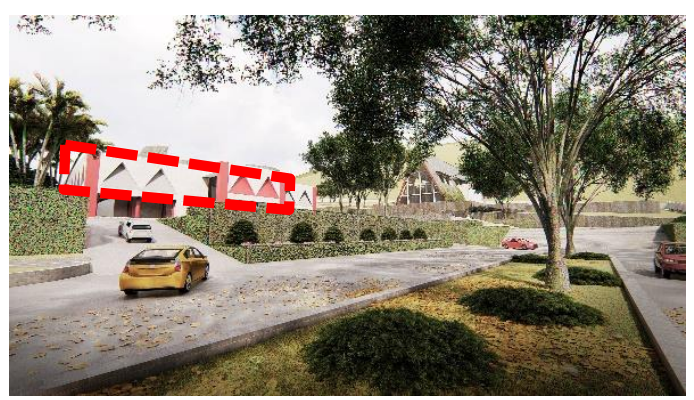

Gambar 16. Bentuk dasar bangunan sopo godang berupa persegi panjang dan segitiga

\section{KESIMPULAN (KONSEP DESAIN)}

Taman sosial budaya Batak berfungsi sebagai wadah untuk melestarikan warisan kebudayaan suku Batak, hal ini bertujuan untuk melindungi/menjaga nilai-nilai luhur dan juga peninggalan-peninggalan nenek moyang suku Batak dapat tetap terjaga. Taman sosial budaya Batak juga akan dijadikan sebagai sebuah destinasi wisata, sebab kebudayaan merupakan 
sebuah aset pariwisata yang dapat berjalan beriringan dan saling mendukung satu sama lain sehingga kebudayaan Batak akan semakin dikenal oleh masyarakat luas.

Pendekatan kearifan lokal digunakan sebagai strategi perancangan untuk menampilkan citra lokal budaya Batak. Sumber-sumber kearifan lokal yang diterapkan yaitu interaksi sosial, arsitektur dan juga persepsi logis kearifan lokal suku Batak. Penekanan kearifan lokal diutamakan pada bagian tampilan bangunan, baik eksterior maupun interior bangunan dengan mengaplikasikan elemen-elemen arsitektur tradisional sebagai. Hal ini bertujuan untuk mmenciptakan citra tradisional/lokal pada bangunan. Elemen-elemen tradisional yang diaplikasikan berupa ornamen gorga, material ijuk, dan juga bentuk geometri segitiga dan persegi. Sedangkan untuk penataan massa dan zona Kawasan mengadopsi persepsi logis suku Batak berupa konsep banua dan konsep dalihan natolu.

Konsep banua diterapkan pada pembagian zoning pada kawasan dimana kawasan dibagi menjadi tiga bagian yaitu banua toru diperuntukkan sebagai entrance pengunjung dan juga sebagai lokasi parkir kendaraan pengunjung. Banua tonga diperuntukkan sebagai zona kegiatan utama berupa museum, sopo godang, dan juga foodcourt\&souvenir shop. Banua ginjang diperuntukkan sebagai area taman arsitektur Batak yang berisi rumahrumah tradisional Batak. Sedangkan konsep Dalihan na tolu diadaptasi menjadi konsep penataan bangunan utama yang berada pada zona banua tonga yaitu bangunan museum, sopo godang, dan juga foodcourt\&souvenir shop.

\section{REFERENSI}

Arimbi, N., Nugroho, R., \& Suparno, S. (2017). TAMAN BUDAYA RAJA ALI HAJI DENGAN PENDEKATAN KEARIFAN LOKAL DI TANJUNGPINANG. ARSITEKTURA, $15,263-268$.

Meliono, I. (2016). Understanding the nusantara thought and local wisdom as an aspect of the Indonesian education. TAWARIKH, 2.
S. P. Napitupulu. (1997). Arsitektur Tradisional Daerah Sumatera Utara. Direktorat Jenderal Kebudayaan.

Soedigdo, D., Harysakti, A., \& Usop, T. B. (2014). I Elemen-Elemen Pendorong Kearifan Lokal pada Arsitektur Nusantara. Jurnal Perspektif Arsitektur| Volume, 9.

Thalia, I., Suastika, M., \& Pramesti, L. (2018). MODERN ARCHITECTURE APPLICATION ON WEDDING CENTRE DESIGN IN SURAKARTA. ARSITEKTURA, 16(1), 67-76. 